\title{
edoc
}

Institutional Repository of the University of Basel

University Library

Schoenbeinstrasse 18-20

CH-4056 Basel, Switzerland

http://edoc.unibas.ch/

Year: 2014

\section{Control of neural stem cell self-renewal and differentiation in Drosophila}

\author{
Kang, Kyung Hwa and Reichert, Heinrich
}

Posted at edoc, University of Basel

Official URL: http://edoc.unibas.ch/dok/A6348153

Originally published as:

Kang, Kyung Hwa and Reichert, Heinrich. (2014) Control of neural stem cell self-renewal and differentiation in Drosophila. Cell \& tissue research, Vol. 359, H. 1. S. 33-45. 
Control of neural stem cell self-renewal and differentiation in Drosophila

Kyung Hwa Kang ${ }^{1^{*}}$ and Heinrich Reichert ${ }^{2}$

${ }^{1}$ KAIST Institute of BioCentury, Korea Advanced Institute of Science and Technology (KAIST), Daejeon 305-701, South Korea.

${ }^{2}$ Biozentrum, University of Basel, Klingelbergstrasse 50/70, $\mathrm{CH}-4056$, Switzerland.

*Correspondence to: Kyung Hwa Kang <kyunghwa.kang@unibas.ch> 


\section{Abstract}

The neural stem cells of Drosophila, called neuroblasts, have the ability to self-renew and at the same time produce many different types of neurons and glial cells. In the central brain and ventral ganglia, neuroblasts are specified and delaminate from the neuroectoderm during embryonic development under the control of proneural and neurogenic genes. In contrast, in the optic lobes, neuroepithelial cells are transformed into neuroblasts postembryonically by a spatial wave of proneural gene expression. Central brain and ventral nerve cord neuroblasts manifest a short embryonic proliferation period followed by a stage of quiescence and then undergo a prolonged postembryonic proliferation period during which most of the differentiated neurons of the adult CNS are generated. While most neuroblasts belong to a type I class that produces neuronal lineages through non self-renewing ganglion mother cells, a small subset of type II neuroblasts generates exceptionally large neuronal lineages through self-renewing intermediate progenitor cells that have transit amplifying function. All neuroblasts in the CNS generate their neural progeny through an asymmetric cell division mode in which the interplay of apical complex and basal complex molecules in the mitotically active progenitor results in the segregation of cell fate determinants into the smaller, more differentiated daughter cell. Defects in this molecular control of asymmetric cell division in neuroblasts can result in brain tumor formation. Proliferating neuroblast lineages in the developing CNS utilize transcription factor cascades as a generic mechanism for temporal patterning and birth order-dependent determination of differential neural cell fate. This contributes to the generation of a remarkable diversity of cell types in the developing CNS from a surprisingly small set of neural stem cell-like precursors. 
Keywords: Neuroblast, Asymmetric cell division, Proliferation, Tumor, Temporal series 


\section{Introduction}

In humans, as in all other higher animals, the central nervous system manifests the highest level of structural and functional complexity of any organ system. The huge diversity of neural cell types that characterize the complex circuits of the nervous system is produced by neural stem cells. During normal development, neural stem cells produce defined sets of neural progeny composed of specific cell types that interconnect to form functional circuitry. Understanding the molecular mechanisms that underlie this process and give rise to the astonishing number and diversity of precisely defined cell types in the nervous system is one of the most challenging problems in biology. In recent years, important contributions to the understanding of the molecular mechanisms involved in neural stem cell biology have been made in several vertebrate and invertebrate neurogenetic model systems, including the fruit fly Drosophila (Homem and Knoblich, 2012).

In Drosophila, the neural stem cells, called neuroblasts, are similar to vertebrate neural stem cells in their ability to self-renew and to produce many different types of neurons and glial cells. The Drosophila central nervous system (CNS), which can be divided into the central brain and optic lobe in the head and the ventral nerve cord (VNC) in the trunk region, consists of thousands of diverse neuronal cells, which are arranged in complicated neural circuits. All of these neuronal cells are generated by a remarkably restricted set of neuroblasts through precisely controlled proliferation and differentiation processes during development. In the last decade, significant progress has been made in understanding the generic developmental mechanisms that operate in these neuroblasts during their normal proliferation. Moreover, some insight into the molecular events by which deregulated neuroblast proliferation can lead to the formation of brain tumors has also been obtained. 
In this review, we consider some of the recent insighs into the mechanisms by which these neuroblasts give rise to diverse neural lineages in CNS development. We first describe the generic series of events that result in the formation, proliferation and termination of neuroblasts in the CNS. We then examine the diversity of neuroblast types with a special focus on the role of transit amplifying neuroblast lineages in brain development. Subsequently we describe a central feature of all neuroblasts namely their ability to self-renew and generate differentiated daughter cells through asymmetric cell divisions, and we also assess how deregulation of this division mode can lead to tumorigenesis. Finally, we review the role of temporal patterning in neuroblasts for the orderly generation of different neural cell types during developmental progression.

\section{The life history of a Drosophila neuroblast}

The basic proliferative elements involved in building the Drosophila CNS are the stem cell-like multipotent neural progenitors referred to as neuroblasts. In the VNC and central brain, neuroblasts first arise by delamination from the neuroectoderm during embryonic development (Fig. 1A). In the embryonic neuroectoderm, groups of cells are singled out as proneural clusters through the expression of genes of the achaete-scute complex and daughterless. In these clusters, neuroblasts become specified by Notch-dependent lateral inhibition from neighboring non-neuroblast cells, in a process in which proneural gene activity is restricted to only the presumptive neuroblast, but not in its neighbors (Artavanis-Tsakonas and Simpson, 1991; Campos-Ortega, 1993; Hartenstein and Wodarz, 2013; Skeath and Thor, 2003). Additionally, members of the Sox transcription factor family have also been reported to be involved in the formation of neuroblasts in a Notch-independent manner (Buescher et al., 2002; Overton et al., 2002). Following their specification, the 
neuroblasts of the VNC and central brain delaminate from the neuroectoderm, enlarge, and begin to proliferate during the short period of late embryogenesis to produce a small set of neurons that make up the simple larval CNS. These embryonically generated neurons are referred to as primary neurons and each neuroblast generates 10-20 primary neurons during embryonic development (Larsen et al., 2009; Lovick et al., 2013).

In the central brain and in the thoracic ganglia, most embryonic neuroblasts enter quiescence in the late embryonic stage (Egger et al., 2008; Younossi-Hartenstein et al., 1996). Exceptions are the four neuroblasts that generate the intrinsic neurons of the mushroom body, along with a fifth brain neuroblast, which do not undergo quiescence, and divide continuously throughout all larval stages to generate exceptionally large lineages of neurons in adult CNS. Neuroblast entry into quiescence is mediated by intrinsically acting Hox genes as well as by temporal identity factors (Tsuji et al., 2008). Following quiescence, most of the remaining neuroblasts enlarge and restart cell division in the late first instar or early second instar of the larva. Re-entrance of the neuroblasts into the cell cycle is triggered by extrinsic signals, including nutritional or hormonal signals such as ecdysone (Colombani et al., 2012; Randhawa and Cohen, 2005). Interestingly, the fat body and a glial cell niche mediate this process. In presence of nutrition, an unknown secreted molecule from the fat body triggers release of the Drosophila insulin like protein (Dilp) from glial cells. Through the insulin receptor (InR), Dilp activates the PI3K/AKTTarget of Rapamaycin (TOR) signaling pathway in neuroblasts and this, in turn, induces the neuroblasts to exit quiescence, increase volume, and re-enter the cell cycle. (Chell and Brand, 2010; Shim et al., 2013; Sousa-Nunes et al., 2011). In contrast to the neuroblasts that undergo quiescence and reactivation, in the abdominal ganglia many of the embryonic neuroblasts are eliminated at late embryogenesis through programmed cell death 
The majority of the neurons that make up the adult central brain and VNC, termed secondary or adult-specific neurons, are generated by neuroblasts postembryonically during a prolonged period of intense proliferative activity which typically lasts from the end of the first laval instar until late larval/early pupal stages (Ito and Hotta, 1992; Prokop and Technau, 1991; Truman and Bate, 1988). Thus, the development of VNC and central brain is accomplished in two distinct periods of neurogenesis, a brief first period in embryonic stages and an extensive second period in larval stages. In the central brain, approximately $90 \%$ of the neurons present in the adult brain are produced postembryonically by a stereotyped array of 100 embryonically derived neuroblast pairs (Technau et al., 2006; Urbach and Technau, 2004).

While these neuroblasts, which can be further divided into type I and type II neuroblasts (see below), arise from the neuroectoderm of the early embryo, the neuroblasts of the optic lobe $(\mathrm{OL})$ are generated from the neuroepithelial cells of the optic anlagen in larval stages (Fig. 1B). During early larval development, the embryonic optic placode generated by invagination of the OL primordium in early embryonic stage, expands dramatically in size through symmetric cell divisions and becomes segregated into two separate epithelia termed inner proliferation center (IPC) and outer proliferation center (OPC). At the medial edge of the OPC, the neuroepithelial cells of the neuroectoderm are sequentially converted into neuroblasts of the medulla, which represents the largest neuropile of the OL (Egger et al., 2007). The dynamic transition of neuroectodermal cells to neuroblasts is triggered by a synchronized medial to lateral wave of expression of the proneural gene lethal of Scute (l'sc), which is more refined by integration of Notch signaling. (Egger et al., 2010, 2011). This neuroepithelium-to-neuroblast transition by the proneural wave is negatively regulated by JAK/STAT signaling and positively 
regulated by Fat-Hippo signaling (Reddy et al., 2010; Yasugi and Mizuno, 2008; Yasugi et al., 2008).

Tight regulation of the precise time at which neuroblasts stop their proliferative divisions is critical for achieving the correct balance of early versus late-born neuronal fate and for the determining the final number of neurons in the mature CNS. In the VNC and central brain, termination of neuroblast proliferation occurs either through apoptosis or by terminal differentiation (Reichert, 2011). Since neuroblasts end their proliferative periods at different times in different regions of the developing CNS, the molecular mechanisms for terminating proliferation are varied for distinct neuroblasts. For example, a pulse of Hox protein expression leads to elimination of specific embryonic and postembryonic neuroblasts in the abdominal ganglia of the VNC, and the activation of pro-apoptotic genes, such as reaper, grim, and hid is involved in this process (Bello et al., 2003; Peterson et al., 2002). Hox gene expression in these neuroblasts is suppressed until the appropriate time by the Polycomb group (PCG) genes (Bello et al., 2007). In contrast, the mushroom body neuroblasts of the central brain, which do not undergo quiescence and continue proliferating until end of the pupal stage, are prevented from premature cell cycle exit by mechanisms that involve Tailless (TII) transcription factor and the leucine-zipper protein Bunched (Kurusu et al., 2009; Siegrist et al., 2010). In the central brain and thoracic ganglia, most neuroblasts disappear due to terminal differentiation, which involves step-wise changes of the neuroblast's cellular properties, including shrinkage of cell size, attenuation of the cell cycle, and expression of homeodomain transcription factor Prospero (Pros), to terminate their proliferation. Pros promotes terminal differentiation of neuroblasts by inducing genes required for the cell cycle exit and the terminal differentiation (Maurange et al., 2008). In many cases, the timing of cell cycle exit of neuroblasts is controlled by the expression of a series of transcription factors (temporal transcription factor series; see below), which is also 
important for generating different cell types in a given neuroblast lineage (Almeida and Bray, 2005; Cenci and Gould, 2005; Maurange et al., 2008).

\section{Diversity of neuroblast types in the CNS}

With few exceptions, almost all neuroblasts in the CNS generate their postmitotic neural progeny through secondary progenitors, that can be either non self-renewing or self-renewing. The so-called type I neuroblasts generate non self-renewing secondary progenitors, referred to as ganglion mother cells (GMCs). Each stem celllike division of the parent type I neuroblast (which self-renews) gives rise to one GMC which in turn divides only once to produce two postmitotic daughter cells, either neurons or glial cells (Fig. 2A). Due to the asymmetric segregation of the Notch signaling inhibitor Numb during this terminal GMC division, one of its daughter cells has active Notch signaling ("Notch-On") while the other daughter has inhibited Notch signaling ("Notch-Off"). This difference translates into lineage-specific differences in the cellular and molecular properties of the two daughters such as axonal targeting, dendritic innervation or survival. Since each type I neuroblast gives rise to numerous GMCs during its period of proliferative activity, its lineage of neural progeny comprises two "hemilineages", one of which is Notch-On while the other is Notch-Off (Karcavich and Doe, 2005; Karcavich, 2005). This generic binary mechanism of asymmetric Notch signaling operating in all neuroblast lineages is an important factor in generating the remarkable neural diversity in the CNS and notably in the central brain and OL of Drosophila (Kumar et al., 2009; Li et al., 2013; Lin et al., 2010; Truman et al., 2010).

All of the neuroblasts in the VNC and most of the neuroblasts in the central brain belong to the type I class. Although their characterization is still incomplete, the 
neuroblasts that generate the medulla neurons of the optic lobe also appear to belong to the type I class (Fig. 2C). In contrast, 8 neuroblasts located in the central brain hemispheres belong to a different class referred to as type II (Bello et al., 2008; Boone and Doe, 2008; Bowman et al., 2008). These type II neuroblasts can be distinguished from type I neuroblasts by the absence of expression of the proneural transcription factor Asense and the cell fate determinant Pros (Bello et al., 2008; Boone and Doe, 2008). Type II neuroblasts generate their lineages of neural progeny through transit amplifying self-renewing secondary progenitors called intermediate neural progenitors (INPs). Each INP undergoes a limited series of proliferative divisions, in each of which it self-renews and generates a GMC which divides once more to produce two postmitotic neural cells (Fig. 2B). Since each type II neuroblast generates numerous INPs and each INP generates several GMCs, a marked amplification of proliferation ensues, and lineages that are 4-5 fold larger than any type I lineages are produced. These remarkably large type II neuroblast lineages comprise up to 500 neural cells and, hence, make a substantial contribution to the complex circuitry of the central brain (Bello et al., 2008; Reichert, 2011). For example, type II neuroblasts generate numerous neural cells, neurons and glia, that contribute to an extensive midline neuropile structure, the central complex of the Drosophila central brain (Izergina et al., 2009; Viktorin et al., 2011). Moreover, and more strikingly, they also contribute to the optic lobe by generating glial cells, which migrate out of the central brain and differentiate into lobula giant glial cells (Viktorin et al., 2013). Interestingly, the pronounced amplification of proliferation achieved in type II neuroblast lineages is balanced by extensive programmed cell death in these lineages, and this likely helps to generate the precise number of differentiated neuron needed in corresponding brain circuitry (Jiang and Reichert, 2012).

Recently, considerable insight into the mechanisms that control proliferation and lineage progression in type II neuroblast lineages, and notably in their INP 
sublineages, has been obtained. Immediately following their generation, INPs are in an immature state characterized cellularly by mitotic inactivity and arrest in the G2 phase and molecularly by the absence of expression of Asense and the bHLH-O transcription factor Deadpan (Bowman et al., 2008). During the following $4-5 \mathrm{~h}$ of cell cycle arrest, INPs mature and acquire the restricted developmental potential necessary for several ensuing asymmetric cell divisions. During each of these cell divisions the mature Asense- and Deadpan-positive INPs self-renew and generate a GMC which gives rise to two neuronal or glia cells (Bayraktar et al., 2010). During the initial asymmetric division of the type II neuroblast, the cell fate determinants Brain tumor (Brat) and Numb are segregated into the INP daughter where they play an essential role to establishing INP potential (Bowman et al., 2008). Numb specifies INP identity by antagonizing the Notch pathway. Brat, on the other hand, contributes to the identity of INPs by blocking their potential dedifferentiation into neuroblast-like progenitors, and this process is likely to be mediated by suppressing the action of the self-renewal factor Klumpfuss through attenuation of $\beta$-catenin/Armadillo activity (Berger et al., 2012; Komori et al., 2014; Xiao et al., 2012). Additional restriction of INP dedifferentiation potential is mediated by dFezf/Earmuff (Erm), which is expressed in mature INPs and prevents their dedifferentiation by activating Prospero to limit proliferation as well as by antagonizing Notch signaling (Weng et al., 2010; Weng and Lee, 2011). Mutation in any one of genes that encode these INP specifying molecules including brat, numb or erm results in the failure of neural differentiation and overgrowth of Type II neuroblasts or INPs (see below) (Bowman et al., 2008; Weng et al., 2010). Recently, several new genes involved in proliferation and differentiation of type I and type II neuroblast have been identified by genome-wide transgenic RNAi screening (Neumuller et al., 2011). Further investigation of these new candidate genes is likely to result in additional information concerning the mechanisms that control neurogenesis in different neuroblast types. 


\section{Neuroblasts proliferate in a stem cell mode}

A defining feature of stem cells is their ability to self-renew and at the same time generate daughter cells, that are committed to further differentiation, in one and the same cell cycle. This feature is usually linked to the ability of stem cells to undergo asymmetric cell divisions. All of the neural stem cell-like neuroblasts in the developing CNS of Drosophila, be they type I, type II, or OL neuroblasts, divide in an asymmetric stem cell mode (Benito-Sipos et al., 2011; Brody and Odenwald, 2000; Egger et al., 2008; Isshiki et al., 2001; Kambadur et al., 1998; Karlsson et al., 2010; Reichert, 2011; Touma et al., 2012; Tran and Doe, 2008). Indeed, many of the basic cellular processes and molecular mechanisms that operate in asymmetric stem cell division have been elucidated in the Drosophila neuroblast models (Januschke and Gonzalez, 2008; Knoblich, 2008; Schaefer and Knoblich, 2001; Wu et al., 2008; Zhong and Chia, 2008). While type I and type II neuroblasts differ in some aspects of their asymmetric cell division modes, a fundamental property of the asymmetric divisions manifested by these neuroblasts is the unequal segregation of proteins that assign cell polarity and cell fate to the two asymmetric daughter cells, the selfrenewing neuroblast and the more differentiated daughter cell (GMC or INP) (Doe, 2008; Homem and Knoblich, 2012; Knoblich, 2008; Neumuller and Knoblich, 2009). This unequal segregation of molecular determinants involves two major molecular complexes that act in the neuroblast during the cell cycle (Fig. 3).

A so-called apical complex is essential for determining the axis of polarity and the orientation of the mitotic spindle in the neuroblast. This apical complex consists of the Par3/Par6/aPKC subcomplex and the Pins/Gai/Mud subcomplex, both of which are localized in the apical region of the neuroblast and are linked via the Inscuteable protein. The Pins/Gai/Mud protein complex is required for proper spindle orientation. 
Mud binds directly to astral microtubules so that Pins/Gai/Mud-Insc-par3/Par6/aPKC can exert a pulling force on the spindle of the dividing neuroblast (Izumi et al., 2006; Kraut and Campos-Ortega, 1996; Kraut et al., 1996; Siller et al., 2006; Speicher et al., 2008). The Par3/Par6/aPKC complex is involved in setting up and maintaining the apical-basal axis of polarity in the neuroblast. This complex is also responsible for the basal localization of cell fate determinants through sequential phosphorylation events that occur in the apical region of the neuroblast (Betschinger et al., 2003; Knoblich, 2008; Wirtz-Peitz et al., 2008; Yamanaka et al., 2006). For example, the mitotically active kinase Aurora A (Aur-A) phosphorylates Par6 resulting in activation of aPKC which then phosphorylates specific cell fate determinants located in the apical region of the neuroblast's cell cortex resulting in their release from the cortex apically and, hence, in their basal accumulation (Fig. 3B).

Three major cell fate determinants, Numb, Brat, and Pros, and two adaptor proteins, Miranda (Mira) and Partner-of-Numb (Pon) make up the so-called basal complex in the proliferating neuroblast. During asymmetric cell division of the neuroblast, these basally localized proteins are segregated into the smaller daughter cell, where they act in promoting differentiation and suppressing proliferation. Numb is a membrane bound Notch inhibitor containing a phosphoserine-binding (PTB) domain. Numb participates in specifying GMC fate by promoting endocytosis of Notch, thus maintaining Notch at a lower level in GMC than that of neuroblast (Bowman et al., 2008; Rhyu et al., 1994; Spana and Doe, 1996; Spana et al., 1995; Uemura et al., 1989; Wang et al., 2007; Zhong et al., 1996). Pros is involved in specifying neuronal and glial cell types in the developing nervous system, and during asymmetric cell division of the neuroblast, Pros is segregated together with Mira into GMC. Upon completion of cell division, Mira is degraded and Pros is released from the cortex and enters into nucleus, where it specifies GMC identity by promoting the expression of GMC-specific genes and repressing the expression of neuroblast-specific genes 
(Atwood and Prehoda, 2009; Choksi et al., 2006; Ikeshima-Kataoka et al., 1997; Li and Vaessin, 2000; Shen et al., 1997). Thus, Prospero negatively regulates the expression of cell cycle genes such as cyclin A, cyclin E, and string, a Drosophila homolog of Ccdc25, and positively regulates the expression of dacapo, a cyclindependent kinase inhibitor. Pros also activates many genes involved in terminal differentiation of neurons such as fasciclin II and netrin B (Choksi et al., 2006). Brat, an $\mathrm{NHL}$ containing translation regulator, is thought to regulate ribosomal protein biosynthesis and to inhibit the transcription factor Myc at the posttranscriptional level. Like with Pros, Brat is exclusively segregated with Mira into the GMC during mitosis and contributes to GMC specification by decreasing protein synthesis (Bello et al., 2006; Betschinger et al., 2006; Lee et al., 2006c).

As in other stem cells lineages, maintaining the precise balance between selfrenewal and differentiation in asymmetrically dividing neuroblast lineages is essential to ensure normal development of the CNS as well as to prevent accumulation of aberrant neural stem cell-like progenitors. Indeed, recent studies using Drosophila neuroblasts have shown that defects in the key molecular mechanisms involved in asymmetric cell division control can result in loss of differentiated cells and uncontrolled overgrowth of neuroblast-like cells leading to brain tumor formation (Bello et al., 2007; Caussinus and Gonzalez, 2005; Chang et al., 2012; Knoblich, 2008) (Fig. 4). Notably, mutations in genes that result in defects in function or asymmetric localization of cell fate determinants such as mutations in Pros, Numb, Brat or in their adaptors Mira and Pon result in massive tumorous overproliferation in the brain due to the production of supernumerary self-renewing daughters at the expense of differentiated cells (Bello et al., 2006; Betschinger et al., 2006; Choksi et al., 2006; Wang et al., 2006a). Neural tumors also result from mutation of other genes involved in asymmetric cell division such as discs large (dlg), lethal giant larva $(\mid g /)$, and scribble (scrib) or the genes encoding the Aur-A and Polo kinases 
(Beaucher et al., 2007; Lee et al., 2006a; Ohshiro et al., 2000; Peng et al., 2000; Reichert, 2011; Wang et al., 2007; Wang et al., 2006b). All of the resulting neural tumor cells undergo massive overgrowth upon transplantation into wild-type hosts, kill the host within weeks, and become immortalized and can be serially transplanted into successive hosts over years (Beaucher et al., 2007; Caussinus and Gonzalez, 2005). These transplanted cells can also exhibit metastatic behavior, migrating away from the site of the primary tumor, passing through several cell layers, and establishing secondary colonies. As might be expected, type II neuroblasts are more susceptible to tumorigenesis, since their lineages comprise two cell types with selfrenewing capability, namely neuroblasts and INPs.

\section{Temporal patterning of neuroblast proliferation}

The ensemble of neuroblasts in the Drosophila CNS can give rise to an astounding diversity of neural cell types. While the molecular mechanisms that make this possible are incompletely understood, the requirement of both positional and temporal information in proliferating neuroblasts for the generation of different neural cell types in its lineal progeny has been firmly established. Positional information is provided to each neuroblast of the central brain and VNC by the early embryonic expression of anteroposterior and dorsoventral patterning genes (Bossing et al., 1996; Broadus and Doe, 1995; Doe, 1992; Doe and Technau, 1993; Schmidt et al., 1997; Urbach and Technau, 2003). These two sets of developmental control genes, which include the Hox genes, the gap genes, the segment polarity genes and the columnar genes, establish a Cartesian grid-like molecular coordinate system in the neuroectoderm, from which the neuroblasts derive. As a result, each neuroblast acquires a specific combination of developmental control genes, which contribute to the specific identity of the neuroblast. As shown by an enormous body of genetic 
evidence, this "combinatorial code" of transcription factors can directly influence the neural cell types that a given neuroblast generates (Skeath, 1999; Skeath and Thor, 2003; Technau et al., 2006; Urbach and Technau, 2004).

In addition to positional information, temporal information is also required in neuroblasts, notably for the generation of different cell types in its lineage of progeny at different times during the proliferation process. The time at which a given progeny is produced and exits the cell cycle is referred to as its birth date, and different progeny are generated by the parent neuroblast in a fixed birth order. The basic molecular mechanism that links birth order to neuronal fate involves a stereotyped temporal series of transcription factors expressed in the parent neuroblast. This temporal transcription factor series was first identified in the proliferating embryonic neuroblasts of the VNC (Fig. 5A), where a serial cascade of transient expression of the five transcription factors Hunchback (Hb), Krüppel (Kr), Pdm, Castor (Cas), and Grainyhead (Grh) takes place (Baumgardt et al., 2009; Benito-Sipos et al., 2010; Brody and Odenwald, 2000; Grosskortenhaus et al., 2005; Grosskortenhaus et al., 2006; Isshiki et al., 2001; Kambadur et al., 1998; Novotny et al., 2002; Pearson and Doe, 2003). The temporal transition of transcription factors is facilitated by crossregulation among these transcription factors, which usually involves both positive feedforward regulation and negative feedback regulation (Baumgardt et al., 2009; Nakajima et al., 2010) However, this cross-regulation is not always required, and is sometimes even sufficient, since loss of one of the transcription factors $\mathrm{Hb}, \mathrm{Kr}$, or Pdm does not result in a blockage of the temporal series but only in the skipping of one temporal identity (Brody and Odenwald, 2000; Grosskortenhaus et al., 2006; Isshiki et al., 2001; Maurange et al., 2008; Tran and Doe, 2008). The specific molecular signals that control the switch in expression from one transcription factor to the next are still unclear. 
Each of the transcription factors in this temporal series is expressed in the proliferating neuroblast during a specific time window, and the GMC that is generated by the neuroblast during that time window inherits the expression of that transcription factor. In consequence, the neurons that derive from the GMC inherit and maintain the expression of the same transcription factor, which is both required and sufficient for their birth order-dependent neuronal specification (Homem and Knoblich, 2012; Li et al., 2014). While the positional information acquired by each neuroblast in a neurogenic array is distinct, the temporal information manifest in proliferating neuroblasts has a more generic character. Many of the neuroblasts in the embryonic VNC manifest the same temporal series of $\mathrm{Hb}, \mathrm{Kr}, \mathrm{Pdm}$, Cas, and Grh expression. However, since different neuroblasts generate different lineal cell types, this temporal series does not control neural cell type per se. Rather it specifies birth orderdependent neural identity, which together with positional identity provided by spatial combinations of transcription factor expression (and with hemilineage-specific Notch signaling) is translated into the specific neural cell types produced in a neuroblast lineage.

Temporal specification is not limited to embryogenesis but also occurs during postembryonic neurogenesis. In VNC neuroblasts two transcription factors, Cas and Sevenup (Svp), act in a postembryonic temporal series; Cas expression in late embryonic neuroblasts is maintained in postembryonic neuroblasts after exit from quiescence and is followed by a wave of Svp expression (Maurange et al., 2008; Zhu et al., 2006). Other members of the postembryonic temporal series must also exist, however, they have not yet been identified. A more complete characterization of a postembryonic temporal series has been carried out in $\mathrm{OL}$ development where a different temporal series of transcriptional factors has been identified (Fig 5B, change from 4). In the OL neuroblasts of the developing medulla, a temporal transcription factor series composed of Homothorax (Hth), Klumpfuss (Klu), Eyeless (Ey), Sloppy- 
paird (SIp), Dichaete (D), and tailless (TII) is expressed (Li et al., 2013; Suzuki et al., 2013). Moreover, crossregulatory interactions are required between some, but not all, of these transcription factors. Mutational inactivation or overexpression of individual members of this temporal series in OL neuroblasts affects birth orderdependent expression of different neuronal markers in the neural cells that are generated by these progenitors implying that the temporal transcription factors control OL neuronal fate. An interesting concatenation of two different temporal transcription factor series is seen during postembryonic development in type II neuroblast lineages (Bayraktar and Doe, 2013). The type II neuroblasts themselves serially express the transcription factors D/Cas and Svp, and more temporal transcription factors are likely to exist as well in these neuroblasts. In addition, each INP daughter cell generated by a type II neuroblast also expresses its own series of temporal transcription factors, namely D, Grh and Ey, in the sublineage of cells that it generates. Mutation or overexpression of the temporal transcription factors in INPS demonstrate the requirement of these factors in fate determination of the lineal neural progeny in INP sublineages, and also show that the sequential expression of these transcription factors is tightly controlled by cross-regulation mechanisms. This type of combinatorial temporal patterning composed by two different axis of temporal transcription factor cascades leads to a larger diversity of neurons and glial cells in complex neural lineages of type II neuroblasts.

Taken together, these findings indicate that virtually all neuroblast lineages in the developing CNS utilize transcription factor cascades as a generic mechanism for temporal patterning and determination of neural cell fate. The specific transcription factor combinations utilized in type I, type II, and OL neuroblasts differs. However, the functional role of the resulting temporal information, integrated together with positional information and binary Notch signaling, is a common one, namely the 
generation of the remarkable diversity of cell types in the developing CNS from a surprisingly small set of neural stem cell-like precursors.

\section{Conclusion}

Drosophila neuroblasts have emerged as an excellent model for understanding the cellular molecular mechanisms involved in neural stem cell self-renewal and differentiation. The genetic basis for the generation of these neural stem cells from the neuroectoderm as well as many of the mechanisms that operate in these primary progenitors during their asymmetric proliferative cell divisions have been elucidated. Moreover, the processes that integrate amplification of proliferation with restricted lineage progression in transit amplifying intermediate progenitors are beginning to be understood. Finally, insight into the combinatorial molecular code that imparts positional and temporal information to neural stem cells as well as the role of these two types of information in specifying the diversity of differentiated neural cell types generated by individual neural stem cells is being obtained. Given the remarkable conservation of molecular mechanisms involved in nervous system development in Drosophila and vertebrates including mammals, the investigations of all of these features of neural stem cell biology in the fly model is likely to help in understanding the roles of neural stem cells in generating the highly complex human brain. From this perspective, the use of the Drosophila model for unraveling the mechanisms underlying neural stem cell derived brain tumors may also lead to important insight into the aberrant molecular mechanisms that cause brain tumors in human patients.

\section{Abbreviations}

aPKC: Atypical protein kinase C, Par3: Partitioning defect 3, Par6: Partitioning defect 6, CNS: Central nerve system, INP: Intermediate neural progenitor, Pon: Partner of Numb, Pins: Partner of Inscuteable, Mud: Mushroom body defect, Gai: G protein a i subunit $65 \mathrm{~A}$ 


\section{Acknowledgements}

We thank Yanrui Jiang for critical reading of the manuscript. This work was supported by grants from the Swiss National Research Program 63 (4063L 128006) and the Swiss National Science Foundation (31003A 140607) as well as by grants from the Global Research Laboratory Program (NRF-2009-00424) and Stem Cell Research Program (NRF-2006-2004289) of the Korean Ministry of Science, ICT, and Future Planning (MSIP). 


\section{References}

Almeida, M.S., and Bray, S.J. (2005). Regulation of post-embryonic neuroblasts by Drosophila Grainyhead. Mechanisms of development 122, 1282-1293.

Artavanis-Tsakonas, S., and Simpson, P. (1991). Choosing a cell fate: a view from the Notch locus. Trends in genetics : TIG 7, 403-408.

Atwood, S.X., and Prehoda, K.E. (2009). aPKC phosphorylates Miranda to polarize fate determinants during neuroblast asymmetric cell division. Current biology : CB 19, 723-729.

Baumgardt, M., Karlsson, D., Terriente, J., Diaz-Benjumea, F.J., and Thor, S. (2009). Neuronal subtype specification within a lineage by opposing temporal feed-forward loops. Cell 139, 969-982.

Bayraktar, O.A., Boone, J.Q., Drummond, M.L., and Doe, C.Q. (2010). Drosophila type II neuroblast lineages keep Prospero levels low to generate large clones that contribute to the adult brain central complex. Neural development 5, 26.

Bayraktar, O.A., and Doe, C.Q. (2013). Combinatorial temporal patterning in progenitors expands neural diversity. Nature 498, 449-455.

Beaucher, M., Goodliffe, J., Hersperger, E., Trunova, S., Frydman, H., and Shearn, A. (2007). Drosophila brain tumor metastases express both neuronal and glial cell type markers. Developmental biology 301, 287-297. Bello, B., Holbro, N., and Reichert, H. (2007). Polycomb group genes are required for neural stem cell survival in postembryonic neurogenesis of Drosophila. Development 134, 1091-1099. 
Bello, B., Reichert, H., and Hirth, F. (2006). The brain tumor gene negatively regulates neural progenitor cell proliferation in the larval central brain of Drosophila. Development 133, 2639-2648.

Bello, B.C., Hirth, F., and Gould, A.P. (2003). A pulse of the Drosophila Hox protein Abdominal-A schedules the end of neural proliferation via neuroblast apoptosis. Neuron 37, 209-219.

Bello, B.C., Izergina, N., Caussinus, E., and Reichert, H. (2008). Amplification of neural stem cell proliferation by intermediate progenitor cells in Drosophila brain development. Neural development 3, 5.

Benito-Sipos, J., Estacio-Gomez, A., Moris-Sanz, M., Baumgardt, M., Thor, S., and Diaz-Benjumea, F.J. (2010). A genetic cascade involving klumpfuss, nab and castor specifies the abdominal leucokinergic neurons in the Drosophila CNS. Development 137, 3327-3336.

Benito-Sipos, J., Ulvklo, C., Gabilondo, H., Baumgardt, M., Angel, A., Torroja, L., and Thor, S. (2011). Seven up acts as a temporal factor during two different stages of neuroblast 5-6 development. Development 138, 5311-5320. Berger, C., Harzer, H., Burkard, T.R., Steinmann, J., van der Horst, S., Laurenson, A.S., Novatchkova, M., Reichert, H., and Knoblich, J.A. (2012). FACS purification and transcriptome analysis of drosophila neural stem cells reveals a role for Klumpfuss in self-renewal. Cell reports 2, 407-418. Betschinger, J., Mechtler, K., and Knoblich, J.A. (2003). The Par complex directs asymmetric cell division by phosphorylating the cytoskeletal protein Lgl. Nature 422, 326-330. 
Betschinger, J., Mechtler, K., and Knoblich, J.A. (2006). Asymmetric segregation of the tumor suppressor brat regulates self-renewal in Drosophila neural stem cells. Cell 124, 1241-1253.

Boone, J.Q., and Doe, C.Q. (2008). Identification of Drosophila type II neuroblast lineages containing transit amplifying ganglion mother cells. Developmental neurobiology 68, 1185-1195.

Bossing, T., Udolph, G., Doe, C.Q., and Technau, G.M. (1996). The embryonic central nervous system lineages of Drosophila melanogaster. I. Neuroblast lineages derived from the ventral half of the neuroectoderm. Developmental biology 179, 41-64.

Bowman, S.K., Rolland, V., Betschinger, J., Kinsey, K.A., Emery, G., and Knoblich, J.A. (2008). The tumor suppressors Brat and Numb regulate transitamplifying neuroblast lineages in Drosophila. Developmental cell 14, 535-546. Broadus, J., and Doe, C.Q. (1995). Evolution of neuroblast identity: seven-up and prospero expression reveal homologous and divergent neuroblast fates in Drosophila and Schistocerca. Development 121, 3989-3996.

Brody, T., and Odenwald, W.F. (2000). Programmed transformations in neuroblast gene expression during Drosophila CNS lineage development. Developmental biology 226, 34-44.

Buescher, M., Hing, F.S., and Chia, W. (2002). Formation of neuroblasts in the embryonic central nervous system of Drosophila melanogaster is controlled by SoxNeuro. Development 129, 4193-4203.

Campos-Ortega, J.A. (1993). Mechanisms of early neurogenesis in Drosophila melanogaster. Journal of neurobiology 24, 1305-1327. 
Caussinus, E., and Gonzalez, C. (2005). Induction of tumor growth by altered stem-cell asymmetric division in Drosophila melanogaster. Nature genetics 37, $1125-1129$.

Cenci, C., and Gould, A.P. (2005). Drosophila Grainyhead specifies late programmes of neural proliferation by regulating the mitotic activity and Hoxdependent apoptosis of neuroblasts. Development 132, 3835-3845.

Chang, K.C., Wang, C., and Wang, H. (2012). Balancing self-renewal and differentiation by asymmetric division: insights from brain tumor suppressors in Drosophila neural stem cells. BioEssays : news and reviews in molecular, cellular and developmental biology 34, 301-310.

Chell, J.M., and Brand, A.H. (2010). Nutrition-responsive glia control exit of neural stem cells from quiescence. Cell 143, 1161-1173.

Choksi, S.P., Southall, T.D., Bossing, T., Edoff, K., de Wit, E., Fischer, B.E., van Steensel, B., Micklem, G., and Brand, A.H. (2006). Prospero acts as a binary switch between self-renewal and differentiation in Drosophila neural stem cells. Developmental cell 11, 775-789.

Colombani, J., Andersen, D.S., and Leopold, P. (2012). Secreted peptide Dilp8 coordinates Drosophila tissue growth with developmental timing. Science 336, 582-585.

Doe, C.Q. (1992). Molecular markers for identified neuroblasts and ganglion mother cells in the Drosophila central nervous system. Development 116, 855-863.

Doe, C.Q. (2008). Neural stem cells: balancing self-renewal with differentiation. Development 135, 1575-1587. 
Doe, C.Q., and Technau, G.M. (1993). Identification and cell lineage of individual neural precursors in the Drosophila CNS. Trends in neurosciences $16,510-514$

Egger, B., Boone, J.Q., Stevens, N.R., Brand, A.H., and Doe, C.Q. (2007). Regulation of spindle orientation and neural stem cell fate in the Drosophila optic lobe. Neural development 2, 1.

Egger, B., Chell, J.M., and Brand, A.H. (2008). Insights into neural stem cell biology from flies. Philosophical transactions of the Royal Society of London Series B, Biological sciences 363, 39-56.

Egger, B., Gold, K.S., and Brand, A.H. (2010). Notch regulates the switch from symmetric to asymmetric neural stem cell division in the Drosophila optic lobe. Development 137, 2981-2987.

Egger, B., Gold, K.S., and Brand, A.H. (2011). Regulating the balance between symmetric and asymmetric stem cell division in the developing brain. Fly 5, 237-241.

Grosskortenhaus, R., Pearson, B.J., Marusich, A., and Doe, C.Q. (2005). Regulation of temporal identity transitions in Drosophila neuroblasts.

Developmental cell 8, 193-202.

Grosskortenhaus, R., Robinson, K.J., and Doe, C.Q. (2006). Pdm and Castor specify late-born motor neuron identity in the NB7-1 lineage. Genes \& development 20, 2618-2627. Hartenstein, V., and Wodarz, A. (2013). Initial neurogenesis in Drosophila. Wiley interdisciplinary reviews Developmental biology 2, 701-721. Homem, C.C., and Knoblich, J.A. (2012). Drosophila neuroblasts: a model for stem cell biology. Development 139, 4297-4310. 
Ikeshima-Kataoka, H., Skeath, J.B., Nabeshima, Y., Doe, C.Q., and Matsuzaki, F. (1997). Miranda directs Prospero to a daughter cell during Drosophila asymmetric divisions. Nature 390, 625-629.

Isshiki, T., Pearson, B., Holbrook, S., and Doe, C.Q. (2001). Drosophila neuroblasts sequentially express transcription factors which specify the temporal identity of their neuronal progeny. Cell 106, 511-521.

Ito, K., and Hotta, Y. (1992). Proliferation pattern of postembryonic neuroblasts in the brain of Drosophila melanogaster. Developmental biology $149,134-148$.

Izergina, N., Balmer, J., Bello, B., and Reichert, H. (2009). Postembryonic development of transit amplifying neuroblast lineages in the Drosophila brain. Neural development 4, 44 .

Izumi, Y., Ohta, N., Hisata, K., Raabe, T., and Matsuzaki, F. (2006).

Drosophila Pins-binding protein Mud regulates spindle-polarity coupling and centrosome organization. Nature cell biology 8, 586-593.

Januschke, J., and Gonzalez, C. (2008). Drosophila asymmetric division, polarity and cancer. Oncogene 27, 6994-7002.

Jiang, Y., and Reichert, H. (2012). Programmed cell death in type II neuroblast lineages is required for central complex development in the Drosophila brain. Neural development 7, 3 .

Kambadur, R., Koizumi, K., Stivers, C., Nagle, J., Poole, S.J., and Odenwald, W.F. (1998). Regulation of POU genes by castor and hunchback establishes layered compartments in the Drosophila CNS. Genes \& development 12, 246260. 
Karcavich, R., and Doe, C.Q. (2005). Drosophila neuroblast 7-3 cell lineage: a model system for studying programmed cell death, Notch/Numb signaling, and sequential specification of ganglion mother cell identity. The Journal of comparative neurology 481, 240-251.

Karcavich, R.E. (2005). Generating neuronal diversity in the Drosophila central nervous system: a view from the ganglion mother cells. Developmental dynamics : an official publication of the American Association of Anatomists 232, 609-616.

Karlsson, D., Baumgardt, M., and Thor, S. (2010). Segment-specific neuronal subtype specification by the integration of anteroposterior and temporal cues. PLoS biology 8, e1000368.

Knoblich, J.A. (2008). Mechanisms of asymmetric stem cell division. Cell 132, 583-597.

Komori, H., Xiao, Q., McCartney, B.M., and Lee, C.Y. (2014). Brain tumor specifies intermediate progenitor cell identity by attenuating betacatenin/Armadillo activity. Development 141, 51-62.

Kraut, R., and Campos-Ortega, J.A. (1996). inscuteable, a neural precursor gene of Drosophila, encodes a candidate for a cytoskeleton adaptor protein. Developmental biology $174,65-81$.

Kraut, R., Chia, W., Jan, L.Y., Jan, Y.N., and Knoblich, J.A. (1996). Role of inscuteable in orienting asymmetric cell divisions in Drosophila. Nature 383, $50-55$.

Kumar, A., Bello, B., and Reichert, H. (2009). Lineage-specific cell death in postembryonic brain development of Drosophila. Development 136, 34333442. 
Kurusu, M., Maruyama, Y., Adachi, Y., Okabe, M., Suzuki, E., and FurukuboTokunaga, K. (2009). A conserved nuclear receptor, Tailless, is required for efficient proliferation and prolonged maintenance of mushroom body progenitors in the Drosophila brain. Developmental biology 326, 224-236. Larsen, C., Shy, D., Spindler, S.R., Fung, S., Pereanu, W., YounossiHartenstein, A., and Hartenstein, V. (2009). Patterns of growth, axonal extension and axonal arborization of neuronal lineages in the developing Drosophila brain. Developmental biology 335, 289-304.

Lee, C.Y., Andersen, R.O., Cabernard, C., Manning, L., Tran, K.D., Lanskey, M.J., Bashirullah, A., and Doe, C.Q. (2006a). Drosophila Aurora-A kinase inhibits neuroblast self-renewal by regulating aPKC/Numb cortical polarity and spindle orientation. Genes \& development 20, 3464-3474.

Lee, C.Y., Robinson, K.J., and Doe, C.Q. (2006b). Lgl, Pins and aPKC regulate neuroblast self-renewal versus differentiation. Nature 439, 594-598. Lee, C.Y., Wilkinson, B.D., Siegrist, S.E., Wharton, R.P., and Doe, C.Q. (2006c). Brat is a Miranda cargo protein that promotes neuronal differentiation and inhibits neuroblast self-renewal. Developmental cell 10, 441-449.

Li, L., and Vaessin, H. (2000). Pan-neural Prospero terminates cell proliferation during Drosophila neurogenesis. Genes \& development 14, 147151.

Li, S., Wang, C., Sandanaraj, E., Aw, S.S., Koe, C.T., Wong, J.J., Yu, F., Ang, B.T., Tang, C., and Wang, H. (2014). The SCFSlimb E3 ligase complex regulates asymmetric division to inhibit neuroblast overgrowth. EMBO reports $15,165-174$. 
Li, X., Erclik, T., Bertet, C., Chen, Z., Voutev, R., Venkatesh, S., Morante, J., Celik, A., and Desplan, C. (2013). Temporal patterning of Drosophila medulla neuroblasts controls neural fates. Nature 498, 456-462.

Lin, S., Lai, S.L., Yu, H.H., Chihara, T., Luo, L., and Lee, T. (2010). Lineagespecific effects of Notch/Numb signaling in post-embryonic development of the Drosophila brain. Development 137, 43-51.

Lovick, J.K., Ngo, K.T., Omoto, J.J., Wong, D.C., Nguyen, J.D., and Hartenstein, V. (2013). Postembryonic lineages of the Drosophila brain: I. Development of the lineage-associated fiber tracts. Developmental biology $384,228-257$.

Maurange, C., Cheng, L., and Gould, A.P. (2008). Temporal transcription factors and their targets schedule the end of neural proliferation in Drosophila. Cell 133, 891-902.

Nakajima, A., Isshiki, T., Kaneko, K., and Ishihara, S. (2010). Robustness under functional constraint: the genetic network for temporal expression in Drosophila neurogenesis. PLoS computational biology 6, e1000760. Neumuller, R.A., and Knoblich, J.A. (2009). Wicked views on stem cell news. Nature cell biology $11,678-679$.

Neumuller, R.A., Richter, C., Fischer, A., Novatchkova, M., Neumuller, K.G., and Knoblich, J.A. (2011). Genome-wide analysis of self-renewal in Drosophila neural stem cells by transgenic RNAi. Cell stem cell 8, 580-593. Novotny, T., Eiselt, R., and Urban, J. (2002). Hunchback is required for the specification of the early sublineage of neuroblast 7-3 in the Drosophila central nervous system. Development 129, 1027-1036. 
Ohshiro, T., Yagami, T., Zhang, C., and Matsuzaki, F. (2000). Role of cortical tumour-suppressor proteins in asymmetric division of Drosophila neuroblast. Nature 408, 593-596.

Overton, P.M., Meadows, L.A., Urban, J., and Russell, S. (2002). Evidence for differential and redundant function of the Sox genes Dichaete and SoxN during CNS development in Drosophila. Development 129, 4219-4228. Pearson, B.J., and Doe, C.Q. (2003). Regulation of neuroblast competence in Drosophila. Nature 425, 624-628.

Peng, C.Y., Manning, L., Albertson, R., and Doe, C.Q. (2000). The tumoursuppressor genes Igl and dlg regulate basal protein targeting in Drosophila neuroblasts. Nature 408, 596-600.

Peterson, C., Carney, G.E., Taylor, B.J., and White, K. (2002). reaper is required for neuroblast apoptosis during Drosophila development. Development 129, 1467-1476.

Prokop, A., and Technau, G.M. (1991). The origin of postembryonic neuroblasts in the ventral nerve cord of Drosophila melanogaster. Development 111, 79-88.

Randhawa, R., and Cohen, P. (2005). The role of the insulin-like growth factor system in prenatal growth. Molecular genetics and metabolism 86, 84-90. Reddy, B.V., Rauskolb, C., and Irvine, K.D. (2010). Influence of fat-hippo and notch signaling on the proliferation and differentiation of Drosophila optic neuroepithelia. Development 137, 2397-2408.

Reichert, H. (2011). Drosophila neural stem cells: cell cycle control of selfrenewal, differentiation, and termination in brain development. Results and problems in cell differentiation 53, 529-546. 
Rhyu, M.S., Jan, L.Y., and Jan, Y.N. (1994). Asymmetric distribution of numb protein during division of the sensory organ precursor cell confers distinct fates to daughter cells. Cell 76, 477-491.

Schaefer, M., and Knoblich, J.A. (2001). Protein localization during asymmetric cell division. Experimental cell research 271, 66-74.

Schmidt, H., Rickert, C., Bossing, T., Vef, O., Urban, J., and Technau, G.M. (1997). The embryonic central nervous system lineages of Drosophila melanogaster. II. Neuroblast lineages derived from the dorsal part of the neuroectoderm. Developmental biology 189, 186-204.

Shen, C.P., Jan, L.Y., and Jan, Y.N. (1997). Miranda is required for the asymmetric localization of Prospero during mitosis in Drosophila. Cell 90, 449458.

Shim, J., Gururaja-Rao, S., and Banerjee, U. (2013). Nutritional regulation of stem and progenitor cells in Drosophila. Development 140, 4647-4656.

Siegrist, S.E., Haque, N.S., Chen, C.H., Hay, B.A., and Hariharan, I.K. (2010). Inactivation of both Foxo and reaper promotes long-term adult neurogenesis in Drosophila. Current biology : CB 20, 643-648.

Siller, K.H., Cabernard, C., and Doe, C.Q. (2006). The NuMA-related Mud protein binds Pins and regulates spindle orientation in Drosophila neuroblasts. Nature cell biology 8, 594-600.

Skeath, J.B. (1999). At the nexus between pattern formation and cell-type specification: the generation of individual neuroblast fates in the Drosophila embryonic central nervous system. BioEssays : news and reviews in molecular, cellular and developmental biology 21, 922-931. 
Skeath, J.B., and Thor, S. (2003). Genetic control of Drosophila nerve cord development. Current opinion in neurobiology 13, 8-15.

Sousa-Nunes, R., Yee, L.L., and Gould, A.P. (2011). Fat cells reactivate quiescent neuroblasts via TOR and glial insulin relays in Drosophila. Nature $471,508-512$

Spana, E.P., and Doe, C.Q. (1996). Numb antagonizes Notch signaling to specify sibling neuron cell fates. Neuron 17, 21-26.

Spana, E.P., Kopczynski, C., Goodman, C.S., and Doe, C.Q. (1995).

Asymmetric localization of numb autonomously determines sibling neuron identity in the Drosophila CNS. Development 121, 3489-3494.

Speicher, S., Fischer, A., Knoblich, J., and Carmena, A. (2008). The PDZ protein Canoe regulates the asymmetric division of Drosophila neuroblasts and muscle progenitors. Current biology : CB 18, 831-837.

Suzuki, T., Kaido, M., Takayama, R., and Sato, M. (2013). A temporal mechanism that produces neuronal diversity in the Drosophila visual center. Developmental biology 380, 12-24.

Technau, G.M., Berger, C., and Urbach, R. (2006). Generation of cell diversity and segmental pattern in the embryonic central nervous system of Drosophila. Developmental dynamics : an official publication of the American Association of Anatomists 235, 861-869.

Touma, J.J., Weckerle, F.F., and Cleary, M.D. (2012). Drosophila Polycomb complexes restrict neuroblast competence to generate motoneurons.

Development 139, 657-666.

Tran, K.D., and Doe, C.Q. (2008). Pdm and Castor close successive temporal identity windows in the NB3-1 lineage. Development 135, 3491-3499. 
Truman, J.W., and Bate, M. (1988). Spatial and temporal patterns of neurogenesis in the central nervous system of Drosophila melanogaster. Developmental biology 125, 145-157.

Truman, J.W., Moats, W., Altman, J., Marin, E.C., and Williams, D.W. (2010). Role of Notch signaling in establishing the hemilineages of secondary neurons in Drosophila melanogaster. Development 137, 53-61.

Tsuji, T., Hasegawa, E., and Isshiki, T. (2008). Neuroblast entry into quiescence is regulated intrinsically by the combined action of spatial Hox proteins and temporal identity factors. Development 135, 3859-3869. Uemura, T., Shepherd, S., Ackerman, L., Jan, L.Y., and Jan, Y.N. (1989). numb, a gene required in determination of cell fate during sensory organ formation in Drosophila embryos. Cell 58, 349-360.

Urbach, R., and Technau, G.M. (2003). Molecular markers for identified neuroblasts in the developing brain of Drosophila. Development 130, 36213637.

Urbach, R., and Technau, G.M. (2004). Neuroblast formation and patterning during early brain development in Drosophila. BioEssays : news and reviews in molecular, cellular and developmental biology 26, 739-751.

Viktorin, G., Riebli, N., Popkova, A., Giangrande, A., and Reichert, H. (2011). Multipotent neural stem cells generate glial cells of the central complex through transit amplifying intermediate progenitors in Drosophila brain development. Developmental biology 356, 553-565.

Viktorin, G., Riebli, N., and Reichert, H. (2013). A multipotent transitamplifying neuroblast lineage in the central brain gives rise to optic lobe glial cells in Drosophila. Developmental biology 379, 182-194. 
Wang, H., Cai, Y., Chia, W., and Yang, X. (2006a). Drosophila homologs of mammalian TNF/TNFR-related molecules regulate segregation of Miranda/Prospero in neuroblasts. The EMBO journal 25, 5783-5793. Wang, H., Ouyang, Y., Somers, W.G., Chia, W., and Lu, B. (2007). Polo inhibits progenitor self-renewal and regulates Numb asymmetry by phosphorylating Pon. Nature 449, 96-100.

Wang, H., Somers, G.W., Bashirullah, A., Heberlein, U., Yu, F., and Chia, W. (2006b). Aurora-A acts as a tumor suppressor and regulates self-renewal of Drosophila neuroblasts. Genes \& development 20, 3453-3463.

Weng, M., Golden, K.L., and Lee, C.Y. (2010). dFezf/Earmuff maintains the restricted developmental potential of intermediate neural progenitors in Drosophila. Developmental cell 18, 126-135.

Weng, M., and Lee, C.Y. (2011). Keeping neural progenitor cells on a short leash during Drosophila neurogenesis. Current opinion in neurobiology 21, 36-42.

Wirtz-Peitz, F., Nishimura, T., and Knoblich, J.A. (2008). Linking cell cycle to asymmetric division: Aurora-A phosphorylates the Par complex to regulate Numb localization. Cell 135, 161-173.

Wu, P.S., Egger, B., and Brand, A.H. (2008). Asymmetric stem cell division: lessons from Drosophila. Seminars in cell \& developmental biology 19, 283293.

Xiao, Q., Komori, H., and Lee, C.Y. (2012). klumpfuss distinguishes stem cells from progenitor cells during asymmetric neuroblast division. Development 139, 2670-2680. 
Yamanaka, T., Horikoshi, Y., Izumi, N., Suzuki, A., Mizuno, K., and Ohno, S. (2006). Lgl mediates apical domain disassembly by suppressing the PAR-3aPKC-PAR-6 complex to orient apical membrane polarity. Journal of cell science $119,2107-2118$.

Yasugi, S., and Mizuno, T. (2008). Molecular analysis of endoderm regionalization. Development, growth \& differentiation 50 Supp/ 1, S79-96. Yasugi, T., Umetsu, D., Murakami, S., Sato, M., and Tabata, T. (2008). Drosophila optic lobe neuroblasts triggered by a wave of proneural gene expression that is negatively regulated by JAK/STAT. Development 135, 1471-1480.

Younossi-Hartenstein, A., Nassif, C., Green, P., and Hartenstein, V. (1996). Early neurogenesis of the Drosophila brain. The Journal of comparative neurology 370, 313-329.

Zhong, W., and Chia, W. (2008). Neurogenesis and asymmetric cell division. Current opinion in neurobiology 18, 4-11.

Zhong, W., Feder, J.N., Jiang, M.M., Jan, L.Y., and Jan, Y.N. (1996).

Asymmetric localization of a mammalian numb homolog during mouse cortical neurogenesis. Neuron 17, 43-53.

Zhu, S., Lin, S., Kao, C.F., Awasaki, T., Chiang, A.S., and Lee, T. (2006).

Gradients of the Drosophila Chinmo BTB-zinc finger protein govern neuronal temporal identity. Cell 127, 409-422. 


\section{Figure legends}

Fig.1 Neurogenesis in the CNS of Drosophila

Drosophila neurogenesis occurs in two distinct periods, at embryonic and larval stage. A, Neuroblasts of the ventral nerve cord derive from the neuroectoderm (NE) by delamination. Proliferating neuroblasts self-renew and generate one ganglion mother cell (GMC) by asymmetric division. The GMC, in turn, divides once more to produce two postmitotic cells, neurons or glia cells. B. Neuroblasts in the postembryonic CNS. Schematic view of the Drosophila CNS in the third instar larva. Different types of neuroblasts are distributed in three anatomically different regions, the central brain $(\mathrm{CB})$, optic lobe $(\mathrm{OL})$, and ventral nerve cord $(\mathrm{VNC})$. The central brain has three different types of neuroblasts, Type I, Type II, and Mushroom body (MB) neuroblast.

Fig.2. Different types of neuroblasts and their proliferation modes

A, Type I neuroblasts(NB) divide asymmetrically to generate one neuroblast and one ganglion mother cell (GMC). The neuroblast self-renews and the GMC divides terminally into two neurons or glia. B, Type II neuroblasts, eight of which are present in each hemisphere of the larval brain divide asymmetrically to generate one selfrenewing neuroblast and one immature intermediate neural precursor (INP) with transit amplifying function. The INP matures through expression of genes that inhibit dedifferentiation and promote lineage progression. Mature INPs produce one immature INP and one GMC through another asymmetric division. C, Optic Lobe neuroblasts are generated by transition from neuroepithelial cells (NE) to neuroblasts induced at the medial edge of the outer proliferation center by a proneural wave. They proliferate in the type I mode. A, apical ; B, basal.

Fig.3 Asymmetric cell division of neuroblasts 
A,Through asymmetric cell division neuroblasts self-renew and simultaneously generate a more differentiated GMC. In the mitotically active neuroblast a Par3/Par6/aPKC protein complex localized asymmetrically at the apical cortex is linked to the Pins/ Gai/Mud protein complex via the scaffolding protein Inscuteable. Cell fate determinants including Pros, Brat, and Numb are asymmetrically localized at basal cortex together with their adaptor proteins, Mira and Pon. During asymmetric cell division, these cell fate determinants are exclusively segregated into the GMC where they induce various differentiation events. B, The apical protein complexes mediate the basal localization of cell fate determinants through protein phosphorylation cascades. Aur-A phosphorylates Par6 to activate aPKC in the complex. aPKC phosphorylates Lgl, Numb, and Mira. Phosphorylated Mira carries Pros and Brat to basal cortex. Polo is also involved in asymmetric protein distribution by phosphorylating Numb and Pon. A, apical ; B, basal.

Fig.4 Defects in asymmetric cell division of neuroblasts cause tumorigenesis

Defects in the molecular machinery involved in asymmetric cell division, including mutations of cell fate determinant genes, pros, brat and numb, cause tumor cell like overgrowth. While the mutant neuroblasts often still divide asymmetrically, their secondary progenitor progeny (GMC in type I neuroblasts and INP/GMC in type II neuroblasts) do not generate differentiated neural cells but rather revert to neuroblast-like cells that continue to divide in an uncontrolled manner. A, Normal neuroblast proliferation leading to differentiated neural cells. B, Mutant neuroblast overproliferation leading to tumorigenesis

Fig.5 Temporal patterning of neuroblast proliferation

A, Embryonic neuroblasts in the VNC express a temporal series of the transcription factors, $\mathrm{Hb}, \mathrm{Kr}, \mathrm{Pdm}$, Cas and $\mathrm{Grh}$ as they age. The temporal transcription factor expressed in the neuroblast is inherited by its GMC and specifies the identity of its 
two neural cell progenies. During embryogenesis, a transient burst of Svp expression is required for the switch from $\mathrm{Hb}$ to $\mathrm{Kr}$ expression. Cas expression is maintained through quiescence and defines the temporal identity of the larval neuroblast until Svp is re-expressed. B, Serial expression of Hth, Klu, Ey, Slp, D, and TII transcription factors in the medulla neuroblasts of the OL during postembryonic development.

C, Combinatorial temporal patterning in type II neuroblast lineages. In addition to a temporal series expressed in the type II neuroblasts, a second different temporal series comprising D, Grh, and Ey is expressed in each INP. Thus two axes of temporal transcription factor cascades interact to generate a large diversity of neural cell types in these lineages. 


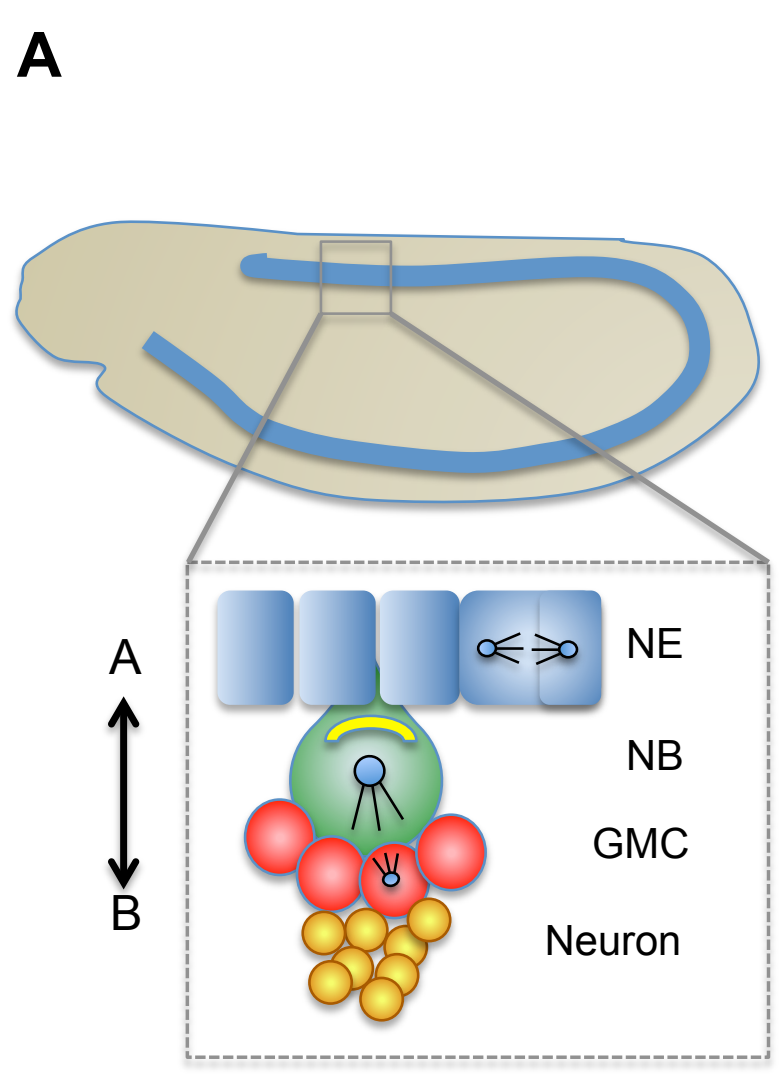

Embryo

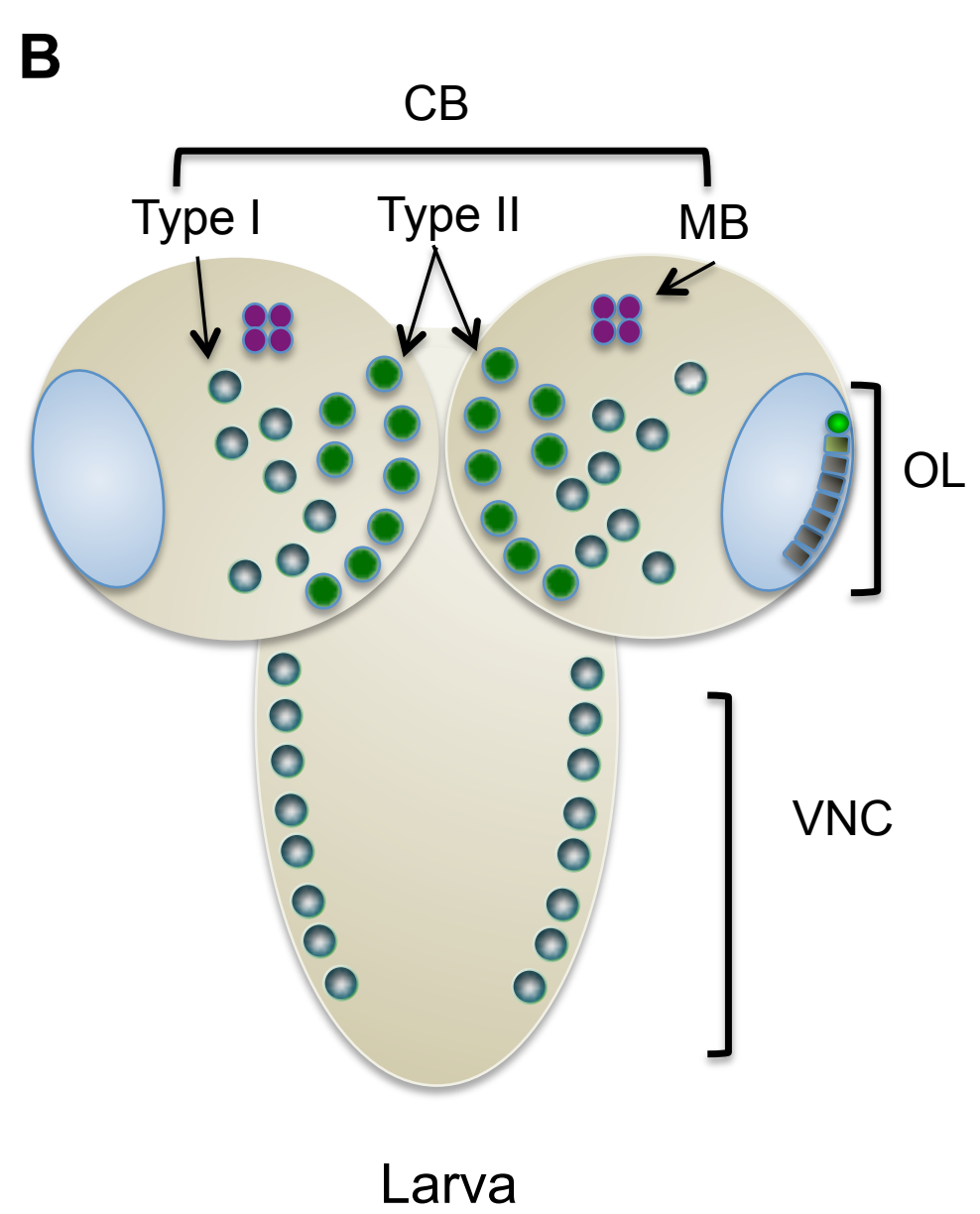


Kang and Reichert Fig.2

A

Typel neuroblast

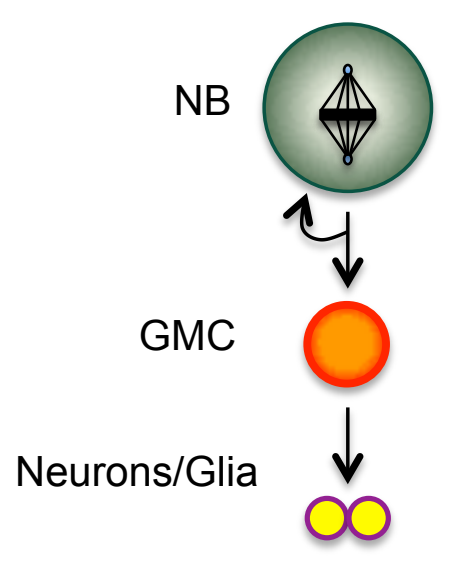

B

Typell neuroblast

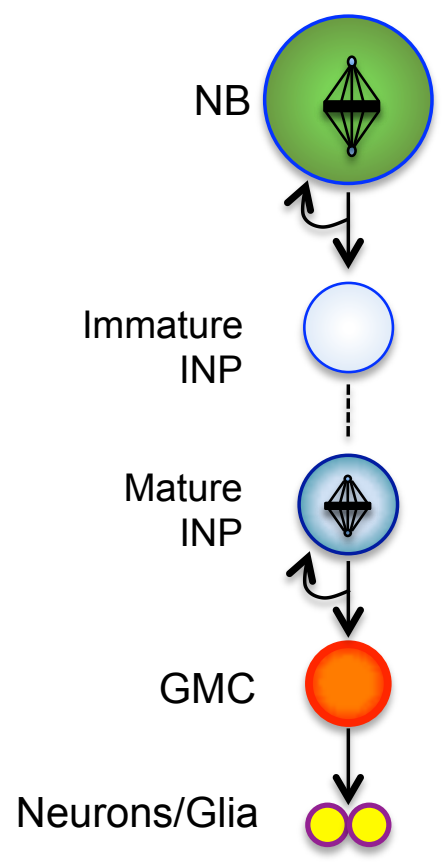

C

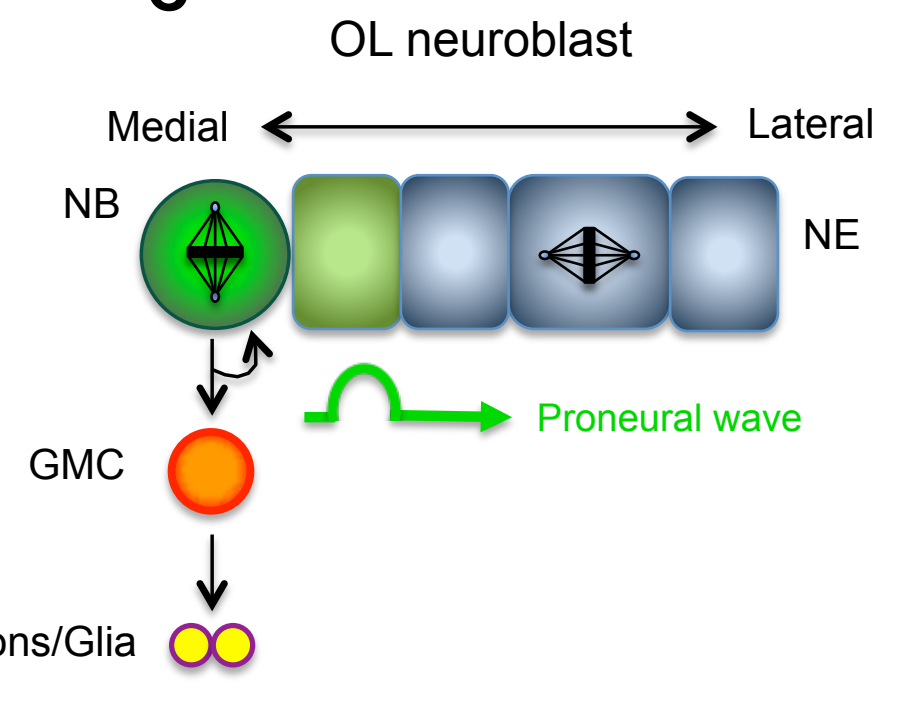

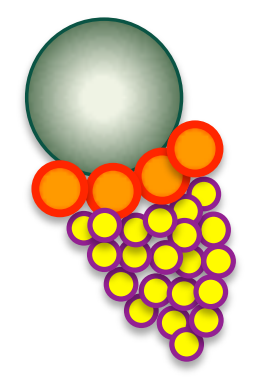
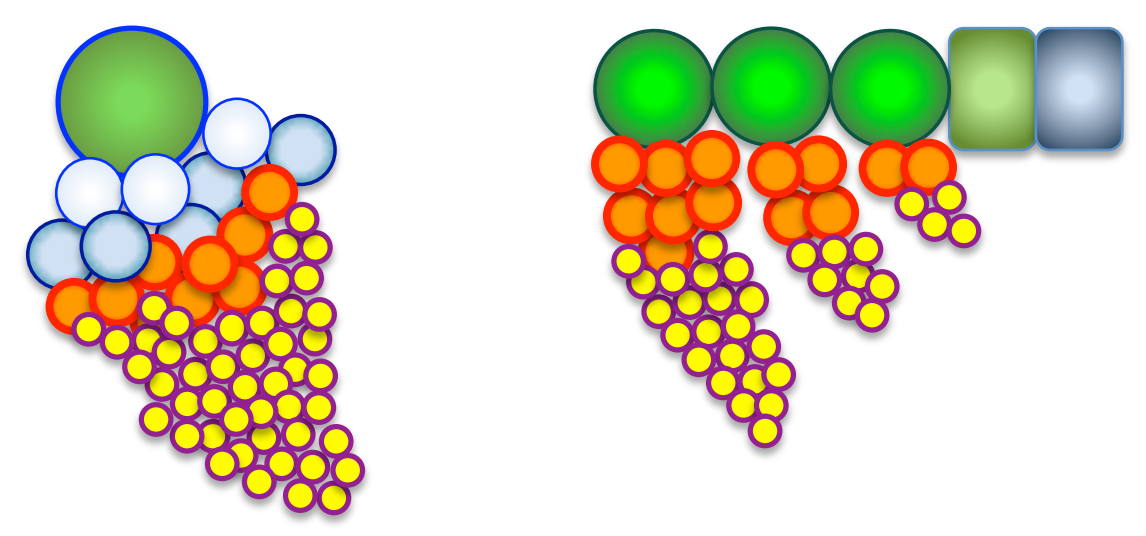
Kang and Reichert Fig.3

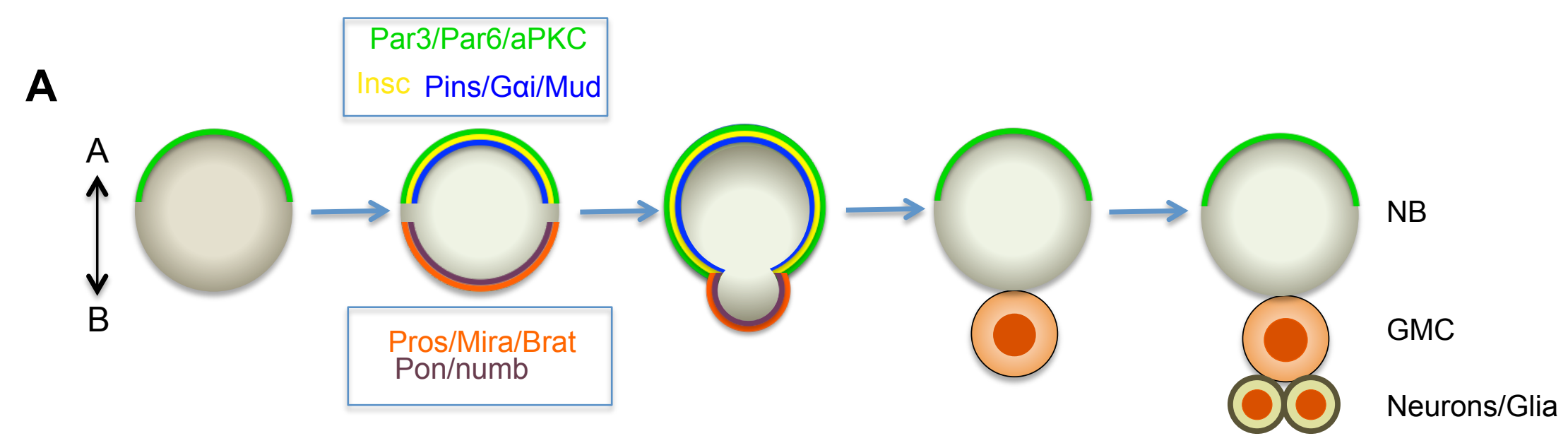

\section{B}

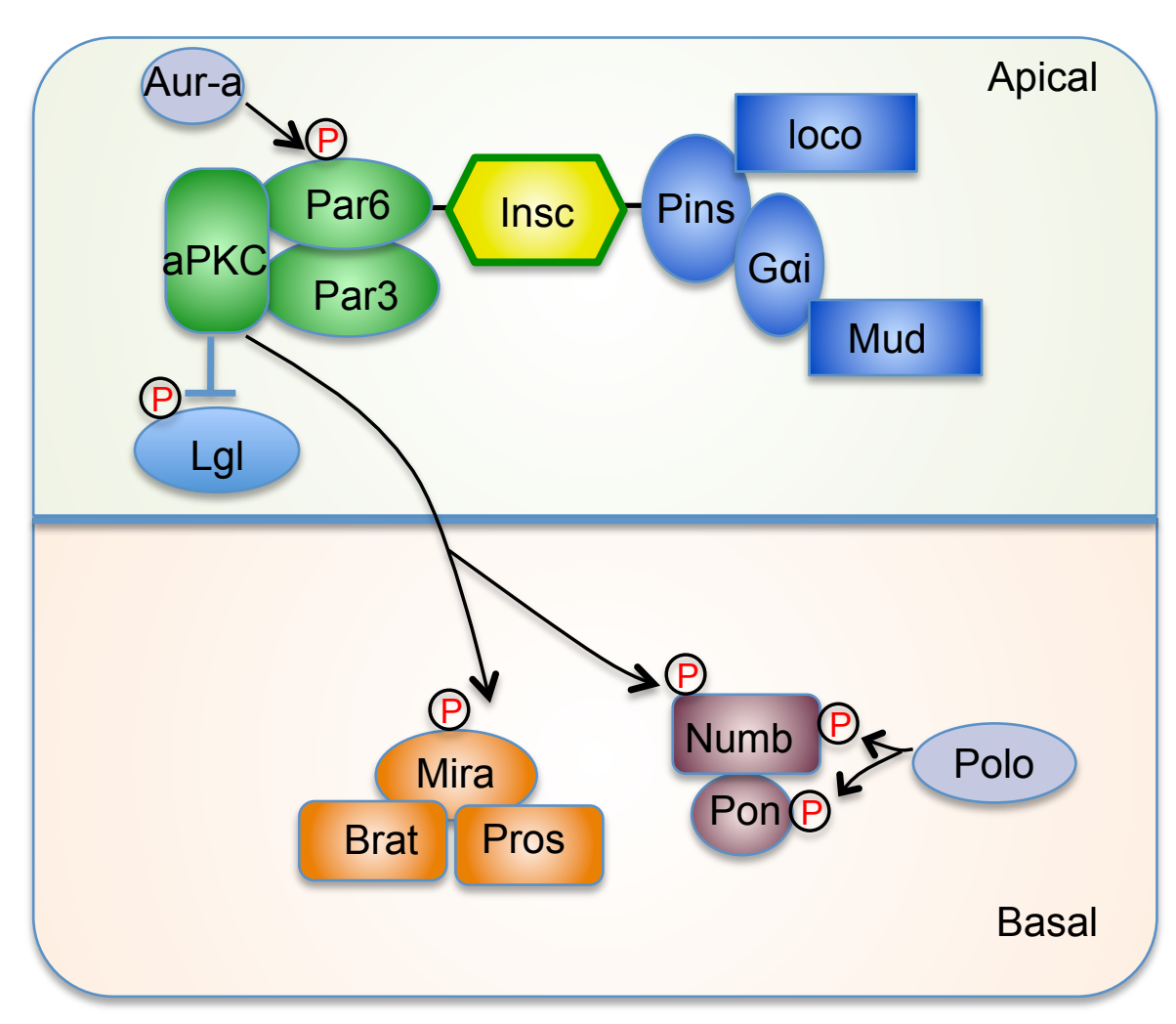


Kang and Reichert Fig.4
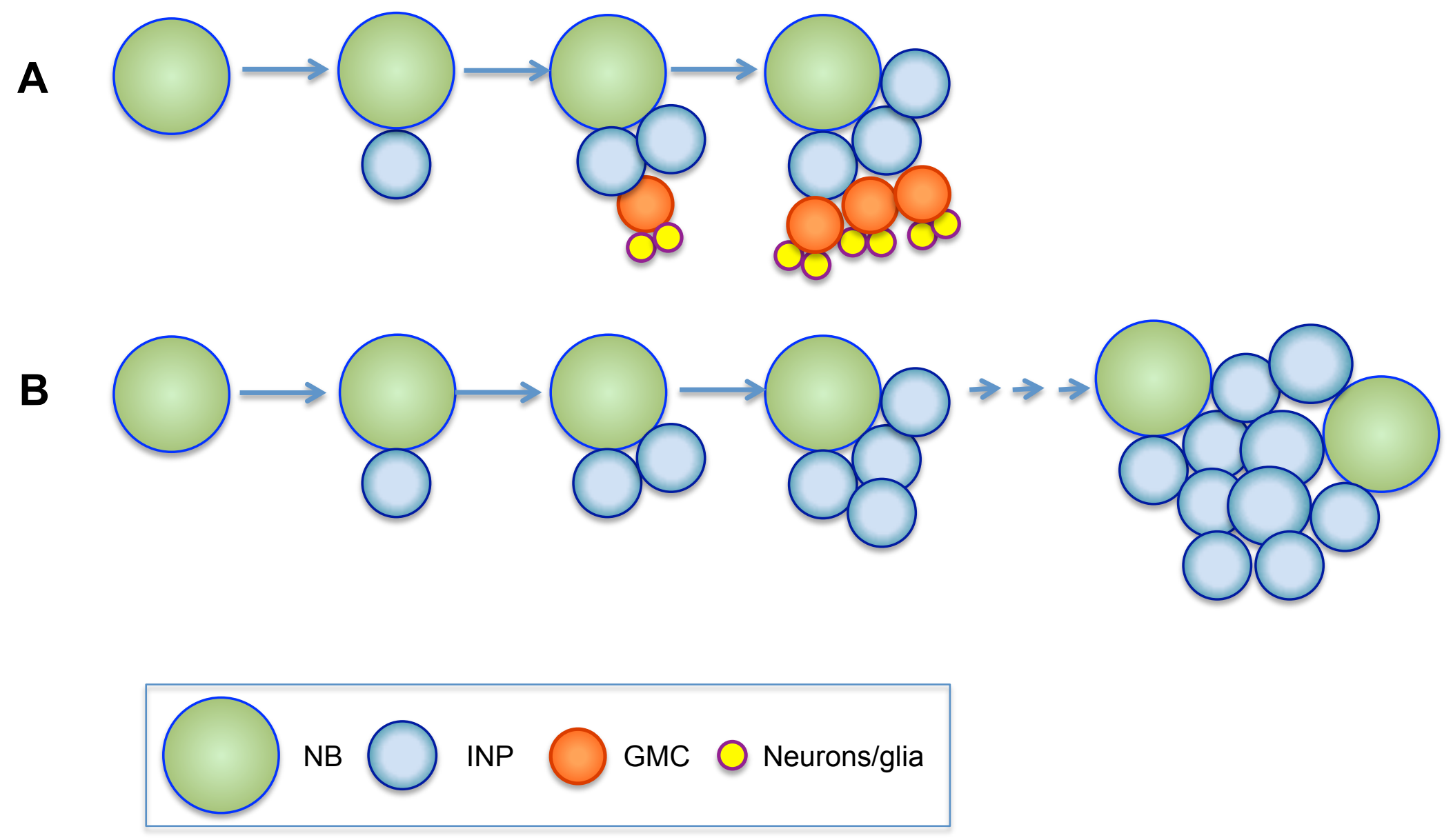
Kang and Reichert Fig.5

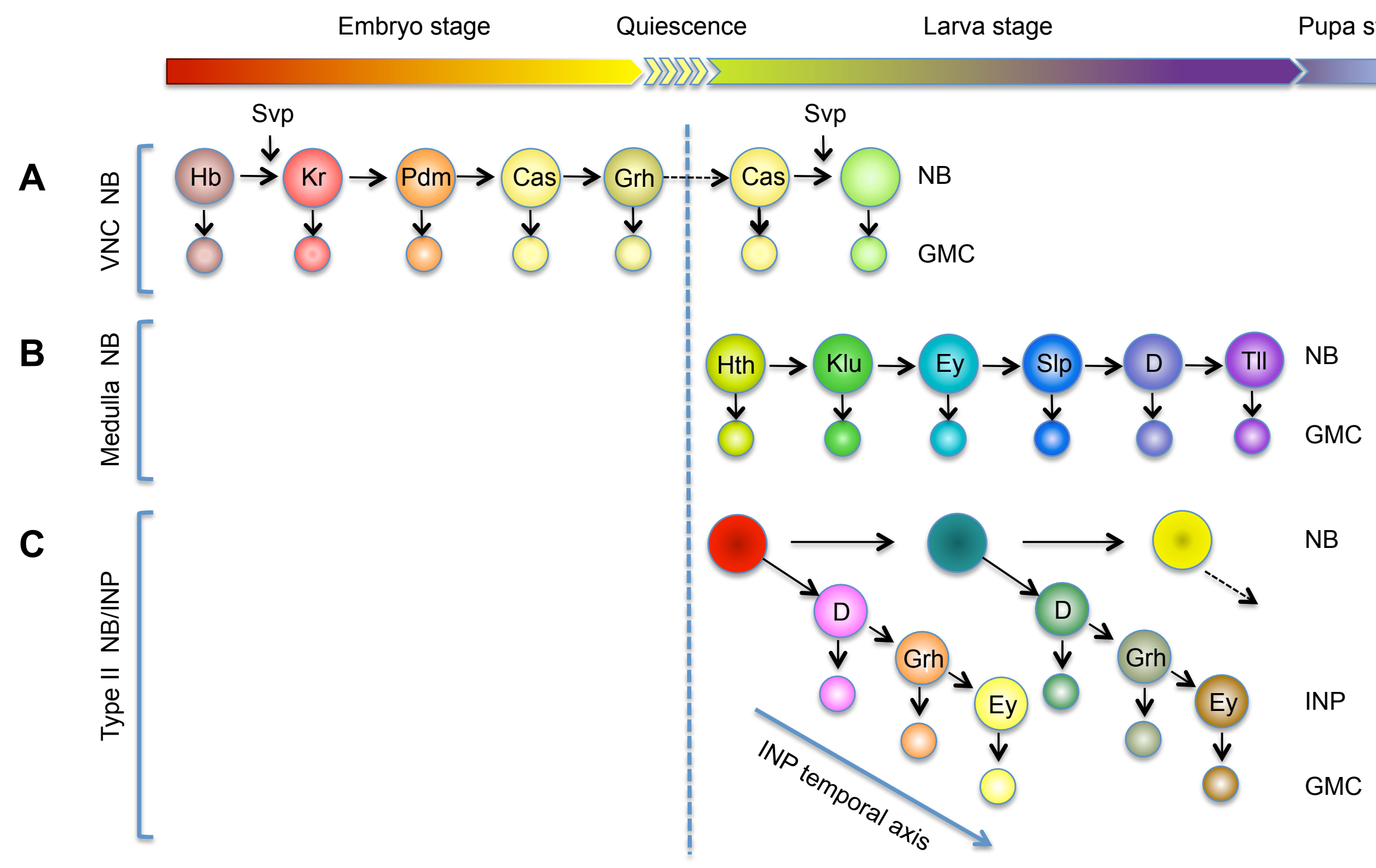

